\title{
Assessing the impact of a journal club elective on literature evaluation performance
}

\author{
Dawn M. Battise, Susan Bates, Sarah A. Nisly \\ Wingate University School of Pharmacy, Wingate, North Carolina, USA
}

\author{
Keywords \\ Elective \\ Journal club \\ Literature evaluation \\ Correspondence \\ Dawn M. Battise \\ Associate Professor of Pharmacy \\ Wingate University School of Pharmacy \\ 515 North Main Street \\ Wingate \\ North Carolina \\ USA 28174 \\ d.battise@wingate.edu
}

\begin{abstract}
Introduction: The study assessed the impact of a journal club (JC) elective on literature evaluation performance during the first three advanced pharmacy practice experiences (APPE). Methods: Students who took a JC elective were compared to students who did not take the JC elective in regards to scores on APPE JC and overall APPE literature evaluation. Results: Of 186 eligible participants, 22 participants completed the JC elective. APPE JC and APPE literature evaluation scores were similar between groups. First semester APPE JC scores were positively correlated with scores earned in the JC elective $(r=0.452, p=0.045)$. Conclusions: Students in the elective did not have significantly different APPE JC scores compared to students who did not take the elective; however, there was a correlation and potential predictive association to APPE JC scores. The JC elective may identify students at risk of lower performance during APPEs so that they may receive additional support.
\end{abstract}

\section{Introduction}

According to the Accreditation Council for Pharmacy Education (ACPE) 2016 standards, a required element of the didactic pharmacy curriculum is the "critical analysis and application of relevant health sciences literature and other information resources" so that students can provide evidence-based recommendations to the public and other healthcare team members (ACPE, 2015; p: 2). However, students often find these portions of the curriculum challenging as they are presented with unfamiliar tasks. Pharmacy schools have incorporated various methods to reinforce these skills, including a journal club (JC) elective course, a spiral model for learning, or problem-based learning (PBL) format (Brady et al., 2013; Beckett et al., 2017; Burris et al., 2019). Yet, an ideal way of developing the skills required for pharmacy students to analyse and apply primary literature has not been established.

There is limited current research investigating the development of literature evaluation skills. Bookstaver and the authors (2011) focused on the Advanced Pharmacy Practice Experience (APPE) preceptor's assessment of students' abilities to evaluate and apply primary literature, as well as students' confidence in their ability to do so. The majority of APPE preceptors agreed that students who had taken an evidence-based medicine (EBM) elective course had developed better skills and greater confidence in critiquing primary literature. All students who had taken the EBM elective course felt confident in their ability to assess primary literature and to apply relevant literature to the clinical setting (Bookstaver et al., 2011). While there were positive changes in perceptions, there was no comparison of grades between those who took the course and those who did not. Arif and the authors (2012) assessed APPE students' perceptions of their own ability to properly evaluate medical literature as well as journal club grade progression. Students felt more confident in understanding study design, strengths, weaknesses, and statistics after taking a druginformation APPE versus an internal medicine APPE (Arif et al., 2012). This study provides information regarding APPE experiences but does not inform schools' didactic curriculum development. An 
additional study evaluated the effect of a JC elective course on Pharmacy Curriculum Outcomes Assessment (PCOA) overall scaled scores, literature evaluation (subtopic) scores and overall acute/ambulatory care APPE scores. They found that students who had taken the JC elective scored higher on the PCOA overall score (24.5 points) as well as the literature evaluation subtopic (11.7\%). Overall acute/ambulatory care APPE scores were $2 \%$ higher for students who had taken the JC elective. Even though they included APPE overall scores, they did not look specifically at APPE JC scores or literature evaluation assessment (Burres et al., 2019).

This retrospective, observational, cohort pilot study evaluates the impact of a journal club elective course on students' APPE literature evaluation and JC scores when compared to students who did not take the elective course.

\section{Methods}

\section{Participants and setting}

Wingate University School of Pharmacy is a four-year Doctor of Pharmacy programme. Drug literature evaluation skills, including JC evaluation, are introduced in the second year and then built upon through the final year in both didactic and experiential courses (Table I). This study included students from 2018 and 2019 graduating classes. All participants had JC scores available from the required Men's and Women's Health (MWH) pharmacotherapy course and completed at least one rotation block in the first APPE trimester. The intervention group completed an additional JC elective course (Table I).

Table I: Summary of literature evaluation incorporation throughout the curriculum

\begin{tabular}{|c|c|c|c|c|}
\hline Course name & Year & $\begin{array}{l}\text { Credit } \\
\text { hour(s) }\end{array}$ & Journal club component & Evaluation \\
\hline $\begin{array}{l}\text { Institutional Pharmacy } \\
\text { Practice IPPE-2 }\end{array}$ & 2 & 2 & $\begin{array}{l}\text { Introduction to basic JC evaluation concepts; students } \\
\text { select a piece of literature with preceptor guidance and } \\
\text { complete a simplified JC worksheet. }\end{array}$ & $\begin{array}{l}\text { Course-specific rubric to assess completed } \\
\text { worksheet }\end{array}$ \\
\hline $\begin{array}{l}\text { Biometrics and } \\
\text { Literature Evaluation }\end{array}$ & 2 & 1 & $\begin{array}{l}\text { Individually or in pairs, students assess an assigned piece } \\
\text { of primary literature. Submit written handout. }\end{array}$ & Course-specific rubric to assess handout \\
\hline $\begin{array}{l}\text { Basic Clinical Skills for } \\
\text { Ambulatory Patient } \\
\text { Care IPPE }\end{array}$ & 3 & 3 & $\begin{array}{l}\text { Varies by preceptor; ranges from informal faculty-led } \\
\text { discussion to more formal student presentations with a } \\
\text { student-developed handout. }\end{array}$ & $\begin{array}{l}\text { Variable; standardised rubric to assess } \\
\text { handout and presentation if the preceptor } \\
\text { requires a formal presentation. }\end{array}$ \\
\hline $\begin{array}{l}\text { Men's and Women's } \\
\text { Health (MWH) } \\
\text { Pharmacotherapy }\end{array}$ & 3 & 2 & $\begin{array}{l}\text { Two to three students assess an assigned piece of primary } \\
\text { literature. Submit written handout. JC evaluation is } \\
\text { presented to peers and one faculty evaluator. }\end{array}$ & $\begin{array}{l}\text { Standardised rubric to assess handout and } \\
\text { presentation }\end{array}$ \\
\hline $\begin{array}{l}\text { Doctoral Candidate } \\
\text { Seminar }\end{array}$ & 3 & 2 & $\begin{array}{l}\text { Individually, students choose two pieces of primary } \\
\text { literature on a selected topic. JC evaluation is offered in a } \\
35-45 \text { minute graded presentation to peers and two } \\
\text { faculty evaluators. }\end{array}$ & $\begin{array}{l}\text { Course-specific rubric to assess handout } \\
\text { and presentation }\end{array}$ \\
\hline Journal Club Elective* & 3 & 1 & $\begin{array}{l}\text { Individually, students choose one piece of primary } \\
\text { literature on a selected topic. JC evaluation is presented in } \\
\text { a } 35-45 \text { minute graded presentation to peers and two } \\
\text { faculty evaluators. Additionally, students are expected to } \\
\text { read articles presented by peers and take a quiz on trial } \\
\text { results. }\end{array}$ & $\begin{array}{l}\text { Standardised rubric to assess handout and } \\
\text { presentation }\end{array}$ \\
\hline APPE & 4 & 5 & $\begin{array}{l}\text { Varies by preceptor; a piece of literature may be assigned } \\
\text { or selected by the student. Students may or may not } \\
\text { submit a written handout. JC evaluation is presented to } \\
\text { preceptors, peers and/or other healthcare providers. }\end{array}$ & $\begin{array}{l}\text { Standardised rubric to assess handout and } \\
\text { presentation, as appropriate }\end{array}$ \\
\hline
\end{tabular}

*not required for all students

$\mathrm{APPE}=$ advanced pharmacy practice experience; IPPE = introductory pharmacy practice experience; JC = journal club

\section{Intervention}

The JC elective course is a one-credit hour, 15-week course graded on a pass/fail basis. Faculty members begin the course with a review of literature evaluation and a sample journal club. After this introduction, students individually present journal clubs to their peers and faculty evaluators (Table I). 


\section{Measures}

A standardised rubric is used across the curriculum to assess student JC performance and build student familiarity with the grading rubric. A 5-point Likert scale with specific descriptors are associated with each component, and the final score is tabulated out of 100. To concentrate on student development, earlier courses in the curriculum use a simplified version of this rubric. However, during the APPE year, students are evaluated on a JC presentation using the standardised rubric. This rubric rates students' ability to assess literature background, methods, results, strengths, limitations, and the ability to apply the information to patient care. The required JC presentation score is entered as a single score within the final APPE evaluation and accounts for $10 \%$ of the overall APPE score.

Beyond a JC presentation, literature evaluation skills are also evaluated during the APPE year. Within all required APPEs, a rubric item assessing complete literature evaluation skills is based on the following criteria: "The student retrieves, analyses, and interprets the professional, lay, and scientific literature to make informed, rational, and evidence-based decisions." This is also evaluated on a 5-point Likert scale with detailed descriptors and converted to a weighted score within the complete APPE evaluation. Literature evaluation skills are assessed during the midpoint and final evaluations.

Journal club rubric scores for the MWH and JC elective were obtained from faculty coordinators. Literature evaluation and JC scores during APPE were obtained from the Core experiential learning management system (CORE Higher Education System, West Warwick, RI) for midpoint and final evaluations. A student's APPE $\mathrm{JC}$ and literature evaluation scores were individually averaged over the first trimester for statistical analysis. Data were collected to note if APPE scores were completed by a faculty or non-faculty preceptor.

Data followed a non-normal distribution, and nonparametric statistical tests were used. Course score distributions and faculty preceptorship were compared between graduation years using a Mann-Whitney $U$ or Chi-Squared, as appropriate. Spearman's correlation coefficients were calculated to evaluate factors influencing average APPE JC scores during the first trimester. Both JC elective and $\mathrm{MWH}$ course scores, preceptorship, and APPE literature evaluation scores were entered into a linear regression analysis. All analyses were performed using SPSS version 25 (IBM, Armonk, NY). The study was exempted from review by Wingate University School of Pharmacy Research Review Board because it used deidentified student scores gathered as a standard part of the curriculum.

\section{Results}

A total of 186 student evaluations were eligible for inclusion, with at least one documented APPE literature evaluation score or APPE JC evaluation score. The participant distribution was even between 2018 and 2019 graduating classes at $47 \%(n=87)$ and $53 \%(n=99)$, respectively. Of these, 22 (10 and 12 students from 2018 and 2019, respectively) participated in the JC elective, and all 186 participated in the MWH course. Participation in the JC elective and faculty preceptorship was similar between graduating classes $(p>0.05)$. Likewise, there were no statistically significant differences between graduating classes and any individual course scores.

Student MWH score and APPE JC score during the first trimester were positively correlated with scores earned in the JC elective $(r 0.516, p=0.014$ and $r 0.452, p=0.045$, respectively) (Table II). Faculty preceptorship and repeat (two or more) faculty preceptors were both negatively correlated with the average APPE JC score (Table III). In a regression analysis, the JC elective score and final APPE literature evaluation score were predictors for the average APPE JC score ( $r$ 0.729, $p=0.005$ ).

Table II: Correlation between scores

\begin{tabular}{lllll}
\hline & $\begin{array}{l}\text { MWH score } \\
\text { (mean } \pm \text { SD) }\end{array}$ & $\begin{array}{l}\text { APPE literature evaluation } \\
\text { midpoint Score } t \\
\text { (mean } \pm \text { SD) }\end{array}$ & $\begin{array}{l}\text { APPE literature evaluation } \\
\text { final score }{ }^{\dagger} \\
\text { (mean } \pm \text { SD) }\end{array}$ & $\begin{array}{l}\text { APPE JC score } \\
\text { (mean } \pm \text { SD) }\end{array}$ \\
\hline JC elective $(n=22)$ & $86.8 \pm 6.4$ & $0.82 \pm 0.1$ & $0.89 \pm 0.08$ \\
\hline Correlation coefficient & $0.516^{*}$ & 0.087 & 0.184 \\
\hline No JC elective $(n=164)$ & $86.9 \pm 7.0$ & $0.84 \pm 0.11$ & $0.91 \pm 0.07$ & $0.452^{*}$ \\
\hline Correlation coefficient & -0.019 & 0.086 & 0.093 & -0.006 \\
\hline
\end{tabular}

APPE = advanced pharmacy practice experience, $\mathrm{JC}=$ journal club, $\mathrm{MWH}=$ men's and women's health, SD = standard deviation ${ }^{*} p<0.05$

$\uparrow$ APPE literature evaluation score in numerical value on a scale of 0 to 1. 
Table III: Comparison of preceptorship and impact on scores during trimester one

\begin{tabular}{llll}
\hline & $\begin{array}{l}\text { Single } \\
\text { faculty } \\
\text { preceptor } \\
(\mathbf{n = 7 2 )}\end{array}$ & $\begin{array}{l}\text { No } \\
\text { faculty } \\
\text { preceptor } \\
(\mathbf{n = 1 0 0 )}\end{array}$ & $\begin{array}{l}\text { Multiple } \\
\text { faculty } \\
\text { preceptors } \\
(\mathbf{n = 1 4 )}\end{array}$ \\
\hline $\begin{array}{l}\text { APPE JC score } \\
\text { for 1 }\end{array}$ & $90.76 \pm$ & $94.58 \pm$ & $88.29 \pm 6.33^{\text {st }}$ \\
trimester & $6.67^{*}$ & 5.24 & \\
(mean \pm SD) & & & \\
\hline
\end{tabular}

APPE = advanced pharmacy practice experience; $\mathrm{JC}=$ journal club; NA = not applicable; SD = standard deviation;

$* p<0.001$ and $r-0.413$

$+p<0.001$ and $r-0.428$

\section{Discussion}

This two-year pilot study provides insight into the impact of repeated exposures to JC experiences prior to APPEs on specific APPE endpoints. Overall, APPE JC scores were numerically similar for those with standard JC exposure in the curriculum as compared to those with additional exposure in the $\mathrm{JC}$ elective. However, participation in the $\mathrm{JC}$ elective resulted in a moderate correlation to APPE JC scores and was predictive of the APPE JC score. This analysis suggests repeated exposure may lead to an increased understanding and performance in literature evaluation skills.

Previously, Burris and the authors (2019) demonstrated that a JC elective accounted for a $1.9 \%$ grade increase on overall cumulative acute and ambulatory care APPE scores; however, this did not explore the impact on APPE score components specifically related to literature evaluation. Although the study accounted for some potential confounders in baseline demographics by using hierarchical testing, additional confounders may have gone unidentified. The JC elective was a twocredit hour course during the second of a three-year programme. The course was offered multiple times during the year, and students could enrol in the course more than once, which allowed for increased student experience. In contrast, the Wingate University School of Pharmacy JC elective is a one-semester, one credit hour course; therefore, students may have more limited opportunities for growth. Additionally, the JC elective is consistently offered in the autumn semester of the third year. It is possible that students do not retain the skills over the months that pass between the end of the elective and the start of APPE, which may result in similar scores for those who have and have not taken the elective. These factors may explain the difference in the reported results as compared to Burris and the authors (2019).

It is interesting that despite similar scores, JC elective scores were predictive of later APPE JC scores. It may be that in the small elective course, individuals at either extreme of score ranges may be more readily identified. In contrast, the MWH JC score was not predictive of APPE JC scores. The MWH score was based on group performance; therefore, lower-performing students may not be as readily identified due to other group member strengths. Additionally, numerous faculty members were involved in grading the $\mathrm{MWH}$ course. The individual presentations and fewer, more consistent evaluators in the $\mathrm{JC}$ elective may result in a more accurate comparison of ability among all students. This may also explain why students in the JC elective had similar MWH JC scores as compared to those who had not taken the elective instead of higher scores as may be expected.

While there is research comparing faculty versus student self-evaluation in the APPE setting, there is limited data comparing faculty vs non-faculty preceptor scores in APPE (Hill \& Kirkwood, 2005; Wagner et al., 2011; Nisly et al., 2019). This study shows that despite the use of a standardised rubric, faculty preceptorship is associated with a statistically significant difference in scores as compared to non-faculty evaluators. Identifying significant score differences between faculty vs non-faculty preceptors raises questions. Is the standardised rubric being consistently used by preceptors, especially non-faculty preceptors who may utilise different institutional evaluation forms? If it is used, is the rubric a reliable, accurate instrument, and, if so, how can inter-rater accuracy be improved? ACPE Standard 24 encourages the use of valid and reliable assessments (ACPE, 2015). However, even reliable rubrics can be fallible if raters do not correctly use them. Data in medicine suggests that rater training for skills assessments may not improve inter-rater reliability, and some suggest training may even cause more stringent scoring without improving accuracy (Cook \& Beckman, 2009; Weitz et al., 2014; Robertson et al., 2018). However, other data demonstrates the benefits of rater training, even for experienced raters (Müller et al., 2003; Angkaw et al., 2006; Feldman et al., 2012; Yuan et al., 2016). Evaluators in this study had varying experience using the provided JC rubric, but overall the evidence suggests providing comprehensive training for both faculty, and non-faculty raters may improve inter-rater reliability and reduce the frequency of rater errors.

Interestingly, although there was a correlation between JC elective scores and APPE JC scores, JC elective scores were not correlated to APPE literature evaluation scores. This may be because this component of the APPE rubric is a more comprehensive assessment of competency beyond JC evaluation, and the JC elective is not designed to thoroughly assess all of these 
abilities. Once again, evaluator bias must also be considered. Despite APPE JC performance, the overall APPE literature evaluation score may be impacted by the halo effect (in which scores may be biased based on a single positive or negative interaction), and training on the APPE evaluation as a whole could prove beneficial (Feldman et al., 2012).

As a pilot study, results are limited by small sample size and missing data points. Additionally, there is no formal evaluator training on JC or APPE rubric use, so, as noted above, despite the use of a standardised rubric, rater errors are possible and may influence results. It is especially notable that preceptor expectations for JC presentations on APPEs can vary widely, and some nonfaculty preceptors may evaluate JC presentations on an alternative rubric that was not provided by the university. Both factors could be the source of significant confounding. Not only could this impact a student's performance on a given elective, but it may also impact later performance due to a lack of consistent JC experience and exposure for all students. However, the study did attempt to limit other confounders. More than one class year was included. Also, faculty teaching the didactic courses were consistent during the study and confirmed that content and evaluation were similar for both years. Finally, it has been shown that scores improve after the third APPE experience, regardless of rotation type, so limiting the analysis to the first trimester reduced potential confounding (Arif et al., 2012).

As a result of this analysis, the institution may consider if early exposure to JCs is being delivered and evaluated in such a way as to identify students at risk of lower performance on future APPEs. In turn, additional support may be offered to these students. To ensure consistent experiences for students across IPPEs and APPEs, in regards to literature evaluation and JC, more standardised expectations may be enforced, such as requiring preceptors to fill out the university approved rubric in the Core experiential learning management system. This will also address concerns about grading variations based on the different assessment tools that some preceptors may be using. If there are still differences between faculty and non-faculty preceptor scores, this may indicate the need to more closely examine the rubric or to provide additional training to preceptors on appropriate rubric use.

Other institutions may benefit from similar quality assurance studies, such as the one described here, to identify the impact of any curricular component on practical experience. Future analysis could include the effect of literature evaluation and JC electives on future student performance, the ability of current JC evaluations to identify students who may need additional support, and the determination of whether scores are consistent across various preceptors.

\section{Conclusions}

Students in a JC elective did not have significantly different APPE JC scores as compared to students who did not take the elective. However, elective JC scores did have a moderate correlation and potential predictive association to APPE JC scores. A JC elective may help identify students at risk of lower performance on APPE JC presentations so that they may receive additional training and support. Additionally, APPE JC scores were significantly different between faculty and non-faculty preceptors, which raises questions about potential programmatic changes, including rater training, to improve rubric validity and inter-rater reliability.

\section{Declaration of interest}

Dawn Battise, Sarah Nisly and Susan Bates do not have any financial disclosures or conflicts of interest to report.

\section{References}

Accreditation Council for Pharmacy Education [ACPE]. (2015). Accreditation standards and key elements for the professional program in pharmacy leading to the doctor of pharmacy degree ("Standards 2016"). https://www.acpeaccredit.org/pdf/Standards2016FINAL.pdf

Angkaw AC, Tran GQ, \& Haaga DA. (2006). Effects of training intensity on observers' ratings of anxiety, social skills, and alcohol-specific coping skills. Behaviour Research and Therapy, 44(4), 533-44. https://doi.org/10.1016/j.brat.2005.04.002

ArifSA, Gim S, Nogid A, \& Shah B. (2012). Journal clubs during advanced pharmacy practice experiences to teach literature-evaluation skills. American Journal of Pharmaceutical Education, 276(5), Article 88. https://doi.org/10.5688/ajpe76588

Beckett RD, Henriksen JA, Hanson K, \& Robison HD. (2017). Teaching student pharmacists to apply drug literature to patient cases. American Journal of Pharmaceutical Education, 81(2), Article 34. https://doi.org/10.5688/ajpe81234

Bookstaver PB, Rudisill CN, Bickley AR, McAbee C, Miller AD, Piro CC, \& Schultz R. (2011). An evidence-based medicine elective course to improve student performance in advanced pharmacy practice experience. American Journal of Pharmaceutical Education, 75(1), Article 9. https://doi.org/10.5688/ajpe7519

Brady JH, Caldwell DJ, Pate KA, \& Pate AN. (2013). An elective course on application of clinical pharmacy principles. American Journal of Pharmaceutical Education, 77(10), Article 216. https://doi.org/10.5688/ajpe7710216 
Burris JN, Frederick EK, Malcom DR, Raake S, Shin M, \& Daugherty KK. (2019). Impact of a journal club elective course on student learning measures. American Journal of Pharmaceutical Education, 83(7), Article 6827. https://doi.org/10.5688/ajpe6827

Cook DA, \& Beckman TJ. (2009). Does scale length matter? A comparison of nine-versus five-point rating scales for the mini-CEX. Advances in Health Science Education, 14(5), 655. https://doi.org/10.1007/s10459-008-9147-x

Feldman M, Lazzara EH, Vanderbilt AA, \& DiazGranados D. (2012). Rater training to support high-stakes simulationbased assessments. Journal of Continuing Education in Health Professions, 32(4), 279-86. https://doi.org/10.1002/chp.21156

Hill LH, \& Kirkwood CK. (2005). Student and preceptor perception of performance in advanced pharmacy practice experiences. American Journal of Pharmaceutical Education, 69(4), 63. https://doi.org/10.5688/aj690463

Kobak KA, Engelhardt N, \& Lipsitz JD. (2006). Enriched rater training using Internet based technologies: a comparison to traditional rater training in a multi-site depression trial. Journal of Psychiatric Research, 40(3), 192-9. https://doi.org/10.1016/j.jpsychires.2005.07.012

Müller MJ, \& Dragicevic A. (2003). Standardized rater training for the Hamilton Depression Rating Scale (HAMD-17) in psychiatric novices. Journal of Affective Disorders, 77(1), 659. https://doi.org/10.1016/S0165-0327(02)00097-6

Nisly SA, Sebaaly J, Fillius AG, Haltom WR, \& Dinkins MM. (2019). Changes in metacognition through self-evaluation during advanced pharmacy practice experiences. American Journal of Pharmaceutical Education, Advance online publication. https://doi.org/10.5688/ajpe7489

Robertson RL, Vergis A, Gillman LM, \& Park J. (2018). Effect of rater training on the reliability of technical skill assessments: a randomized controlled trial. Canadian Journal of Surgery, 61(6), 405. https://doi.org/10.1503/cjs.015917

Wagner ML, Churl Suh D, \& Cruz S. (2011). Peer-and self-grading compared to faculty grading. American Journal of Pharmaceutical Education, 75(7), Article 130. https://doi.org/10.5688/ajpe757130

Weitz G, Vinzentius C, Twesten C, Lehnert H, Bonnemeier H, \& König IR. (2014). Effects of a rater training on rating accuracy in a physical examination skills assessment. GMS Zeitschrift für Medizinische Ausbildung, 31(4). https://doi.org/10.3205/zma000933

Yuan CM, Nee R, Abbott KC, \& Oliver III JD. (2016). Combating grade inflation in nephrology clinical rotation evaluations using faculty education and a 5-point centered rating scale. Journal of Graduate Medical Education, 8(2), 191-6. https://doi.org/10.4300/JGME-D-15-00218.1 